\title{
Exercise is medicine and physicians need to prescribe it!
}

\author{
$\checkmark$ R E Sallis \\ EDITOR'S \\ CHOICE
}

The three major factors that influence our health and longevity are genetics, the environment and behaviour. Because we have very little control over genetic factors, it is critical that we focus on the environmental and behavioural factors we can control to improve health. Whereas great strides have been made in reducing the environmental factors influencing disease, such as through vaccinations, hygiene and safety regulations, little has been done to target behavioural factors such as physical inactivity. It is tragic that so little has been done to address the one major factor affecting our health and longevity that is almost entirely under our control. At this point in time, I believe physical inactivity has become the greatest public health problem of our time and finding a way to get patients more active is absolutely critical to improving health and longevity in the 21 st century.

The beneficial relationship between exercise and health has been well known dating back to the 5 th century $\mathrm{BC}$, when Hippocrates said that "Eating alone will not keep a man well; he must also take exercise. For food and exercise... work together to produce health". ${ }^{1}$ This relationship has been further defined by years of scientific research that shows a clear correlation between physical activity and health status. That is, those individuals who maintain an active and fit way of life live longer and healthier lives than those who do not. This association between physical activity and health persists in virtually every subgroup of the population, regardless of age, sex, race or environmental condition. ${ }^{2}$

\section{THE SCIENCE BEHIND PHYSICAL ACTIVITY AND HEALTH}

There is clear scientific evidence proving the benefit of regular physical activity on both the primary and secondary prevention of diabetes, hypertension, cancer (particularly breast and colon cancer),

Kaiser Permanente Medical Center, Department of Family Medicine, Fontana, California, USA

Correspondence to: Dr R E Sallis, Medicine and Sports Medicine, 10850 Arrow Route, Rancho Cucamonga, CA 91730, USA; robert.e.sallis@kp.org depression, osteoporosis and dementia. Furthermore, regular physical activity has been shown to be essential in achieving and maintaining weight control. Finally, there is a clear correlation between physical activity and all-cause mortality. ${ }^{3}$ Without a doubt, exercise really is medicine and, in fact, it can be seen as the much needed vaccine to prevent chronic disease and premature death.

So armed with all this knowledge, why has organised medicine not declared an allout war against physical inactivity? If we had a pill that conferred all the confirmed health benefits of exercise, would we not do everything humanly possible to see to it that everyone had access to this wonder drug? Would it not be the most prescribed pill in the history of mankind? I think we all know the answer to these questions. We know that the immensely powerful pharmaceutical machine that exists in the world at present would see to it that everyone knew about this pill and that the healthcare systems of the world would pay for it, no matter what the cost.

\section{ECONOMIC FACTORS}

Beyond the effects of physical activity on morbidity and mortality, there are clear economic reasons to try and increase physical activity among our patients. We know that compared with active patients, sedentary patients cost over US\$1500 more per year to care for. ${ }^{4}$ In California alone, the medical costs attributed to inactivity were estimated at US\$29 billion in the year 2005 . This figure represented a $32 \%$ increase from the same cost estimate in 2000. ${ }^{5}$ At Kaiser Permanente in southern California (USA), we spend US\$1 out of every US\$10 on caring for patients with diabetes, the vast majority of whom have type 2 diabetes-a condition that can be cured or markedly improved by a regimen of regular physical activity and proper diet. It is clear that the spiraling cost of inactivity is going to break the bank for healthcare spending if dramatic changes are not made.

For this reason, our leadership at Kaiser Permanente in southern California has made a major commitment to getting our patients more active. We record physical activity as a vital sign and believe that there is no greater indicator of an individual's health and longevity than how many minutes per week he or she exercises. For this reason, at every visit patients are asked two questions during their intake while vital signs are measured: "on average, how many days per week do you engage in at least moderate (brisk walk or greater) exercise" and "on average, how many minutes per session"? These two numbers are then multiplied to give us a patient's minutes per week of moderate or greater exercise. In keeping with recommendations from the American College of Sports Medicine (ACSM) and the American Heart Association, we aim for a goal of at least 150 minutes per week of moderate exercise for our adult patients.

Because we have an electronic medical record at Kaiser Permanente, we are able to identify patients who are sedentary and thus at risk of chronic disease and premature death. This risk factor is particularly important in patients who have other concurrent risk factors such as diabetes or smoking. Knowing the activity level of our patients allows us to target those most at risk with interventions designed to increase physical activity, such as our physical activity telephone help-line. This help-line is manned by a counsellor who reviews a patient's current activity level and then mails out a pedometer with clear instructions on how to use it and appropriate goals for daily step counts. They then make three more follow-up calls over the next few months to monitor compliance and provide encouragement.

The commitment to getting patients at Kaiser Permanente more active fits well with our national advertising campaign called "Thrive". The tag line for this campaign is "at Kaiser Permanente we want you to live well, be well and thrive!" A central theme of this campaign all along has been the importance of getting patients more active and interested in taking care of themselves. It is clear this message has resonated with patients and the "Thrive" campaign has become one of the most successful advertising campaigns ever launched in the healthcare industry.

\section{EXERCISE IS MEDICINE}

As a practising family physician for the past 20 years and a long-time member of the ACSM, I have become very sensitive to the fact that mainstream medicine has mostly ignored research on the exercise pill. Instead, the healthcare system as it exists currently is completely enamoured with procedures and pharmaceuticals, while paying little more than lip service to prevention. It was against this backdrop 
that my major focus as ACSM president last year was to advocate for making physical activity assessment and prescription a standard part of the disease prevention and treatment paradigm. Certainly, current evidence calls for nothing less than a global initiative to make this happen.

As luck would have it, last year's president of the American Medical Association was Dr Ron Davis. Ron is a preventive medicine physician and head of the Center for Health

\section{What is already known on this topic}

- There is clear evidence proving the benefits of regular physical activity in the prevention of chronic disease and lowering of mortality rates.

- Inactivity-related diseases account for a significant and growing cost for healthcare systems.

- Little is being done by organised medicine to try and increase physical activity among patients.

\section{What this paper adds}

- This paper suggests that healthcare systems must begin to think of exercise as a medication that should be prescribed to patients.

- There should be a merging of the fitness industry with the healthcare industry, so that patients can be better helped to find an appropriate fitness regimen.

- "Exercise is Medicine" is a new initiative jointly sponsored by the American College of Sports Medicine and the American Medical Association, which aims to make activity assessment and prescription a standard part of the disease treatment and prevention paradigm.
Promotion and Disease Prevention of the Henry Ford Health System in Detroit, Michigan, USA. The idea that exercise prescription should become a standard of practice for organised medicine was shared by Ron and he convinced the American Medical Association to partner with ACSM on an initiative called Exercise Is Medicine (see www.exerciseismedicine.org). A national launch for this initiative was held on 5 November 2007 at the National Press Club in Washington, DC, USA. Also attending the launch was the acting US Surgeon General, Dr Steven Galson, who is also a strong advocate for promoting physical activity to influence health, along with Melissa Johnson (Executive Director of the President's Council on Physical Fitness and Sports) and Jake Steinfeld (Chairman of the California Governor's Council for Physical Fitness and Sports).

\section{CHANGING PARADIGMS}

It is clear to me that we must begin to merge the fitness industry with the healthcare industry if we are going to improve world health. No one can argue that there are many individuals and organisations out there in the fitness world who know how to get people more active and make a living doing it. Why does this fitness world seldom intersect with the healthcare world? Why can I, as a family physician in America, refer my patient to a bariatric surgeon and have insurance cover the cost of stomach stapling, yet the same insurance plan will not pay for an appointment with a fitness professional? This simply makes no sense and has to change.

I believe that sports medicine physicians around the world are the best advocates for Exercise Is Medicine. We must collectively urge all patients to become more active and stay active throughout their lives. It is imperative that all patients understand the risks of being sedentary and the importance of exercise in treating and preventing chronic disease. We must also insist that the healthcare systems of the world make as big (or bigger) a commitment to getting patients active as they make to getting them to take medications or submit to various procedures that have less scientific evidence supporting their benefit.

For these reasons, I was very excited to hear that the British Journal of Sports Medicine has dedicated a special issue to the theme of "Exercise Is Medicine". Dr Steve Blair, the guest editor of this special issue, has dedicated his amazing career to proving scientifically that exercise is medicine and is responsible for much of the evidence base behind it. With a wealth of evidence in hand, it is time for organised medicine to join with fitness professionals to ensure that patients around the world take their exercise pill. There is no better way to improve health and longevity.

Competing interests: Declared. RES is a partner in the Kaiser Permanente Medical Centre in California, USA.

Accepted 13 October 2008

Published Online First 29 October 2008

Br J Sports Med 2009;43:3-4.

doi:10.1136/bjsm.2008.054825

\section{REFERENCES}

1. Hippocrates. Jones WH, trans. Regimen I. Cambridge: Harvard University Press, 1952.

2. Pate RR, Pratt M, Blair SN, et al. Physical activity and public health: a recommendation from the Centers for Disease Control and Prevention and the American College of Sports Medicine. JAMA 1995;273:403-7.

3. US Department of Health and Human Services. Physical activity and health: a report from the Surgeon General. Atlanta, GA: Centers for Disease Control and Prevention, National Center for Chronic Disease Prevention and Health Promotion, 1996.

4. Anderson LH, Martinson BC, Crain AL. Health care charges associated with physical inactivity, overweight, and obesity. Prev Chronic Dis 2005;2:A09

5. Chenoweth and Associates Inc. The economic costs of physical inactivity, obesity, and overweight in California adults. Sacramento, CA: Cancer Prevention and Nutrition Section, California Center for Physical Activity, California Department of Health Services, 2005. 